Arteterapia. Papeles de arteterapia y educación para inclusión social ISSN: $1886-6190$

\title{
Pintarme las manos: proceso pre-representacional en Arteterapia
}

\author{
Viviana Rodríguez González ${ }^{1}$
}

Recibido: 17 de julio de 2016 / Aceptado: 1 de septiembre de 2016

Resumen. En este artículo se desea reivindicar la posibilidad de cambio que permite el Arteterapia gracias a su lenguaje meramente no-verbal. Es bien sabido que el Arteterapia tiene una cualidad particular que no es propia de los tratamientos convencionales. Queremos adentrarnos en estas cualidades para mostrar, con un ejemplo práctico, lo que nos distingue y comenzar así a animar a otros profesionales de esta disciplina a profundizar y estudiar dichas cualidades. Presentaremos el trabajo de interacción de Arteterapia, con los materiales y con el espacio utilizado, de una niña de 4 años de edad que presentaba hiperactividad, derivada de haber vivido situaciones altamente estresantes. A través de dicha interacción (en este caso gracias al trabajo con témperas) esta niña pudo bajar su activación corporal y comenzar un recorrido desde la pre-representación a representación.

Palabras clave: Arteterapia; hiperactividad; juego, niños; refugiados; trauma.

\section{[en] Painting my hands: A pre-representational Art Therapy journey}

\begin{abstract}
This article intends to show the possibility of change that allows Art Therapy with its purely non-verbal language. It is well known that Art Therapy has a particular quality that is not typical of conventional treatments. These qualities will be discussed showing a practical example as to what distinguishes us, looking to motivate other professionals of this discipline to deepen and study them. The interaction in an Art Therapy space and materials are presented thru the case of a four year old girl who's presented hyperactivity behavior derived from the experience of highly stressful situations. Through the interaction with materials like tempera colors this girl lowers the body activation and start a journey from pre-representation to representation.
\end{abstract}

Keywords: Art therapy; child; hyperactivity; play; refugees; trauma.

Sumario. 1. Introducción al caso; 2. Lenguaje no-verbal; 3. Neurociencia y trauma; 4. Experiencias Sensoriales: el uso del material plástico en Arteterapia; 5. Sobre ensuciar y desordenar en Arteterapia. 6. Pasar de la experimentación a la obra plástica; 7. Registro del trabajo plástico; 8. Conclusiones; 9. Referencias bibliográficas.

Cómo citar: Rodríguez González, V. (2016) Pintarme las manos: proceso pre-representacional en Arteterapia, en Arteterapia. Papeles de arteterapia y educación para inclusión social 11, 241-252.

1 Psicóloga Sanitaria y Arteterapeuta por la Universidad de Barcelona. Miembro acreditado de la Ate, Asociación Profesional Española de Arteterapeutas y de ANDART, Asociación Profesional Andaluza de Arteterapia.

E-mail: arteterapiamalaga@gmail.com 


\section{Introducción al caso}

La niña de 4 años de edad, a la que llamaremos MA, cumplía con algunos indicadores de trauma por estrés post traumático en niños, por haber vivido en una zona de conflicto armado, y que durante el proceso de la terapia cumplió los 5 años de edad. Vive con su familia en un centro de acogida para solicitantes de asilo o protección internacional.

Los indicadores de trauma en niños que mostraba eran:

- Hiperactividad.

- No confiar en quienes no fueran sus cuidadores.

- Juego repetitivo.

La hiperactividad se traducía en un estado de alerta continuo, por ejemplo, aunque no se percibía asustada en las sesiones, durante las mismas, salía de la sala o paraba la actividad cuando escuchaba un ruido, y para comprobar que sus padres estaban cerca. En las primeras sesiones no paraba de moverse ni de sacar juguetes $\mathrm{y}$, cuando jugaba, se implicaba por muy poco tiempo, convirtiéndose más bien en un juego de descarga, como por ejemplo, tiraba muñecos al vacío que después rescataba, una y otra vez.

La primera intención era aplicar el Protocolo CATT, "Children Accelerated Trauma Therapy" (Raby, 2011), comenzando con desarrollar la relación terapéutica a través de la Arteterapia y el juego. El protocolo CATT encuadra una serie de fases para tratar el TEPT "Trastorno de Estrés Postraumático" en niños donde se aplica una técnica cognitiva que utiliza el arte y el juego para procesar memorias traumáticas. Esto no se llegó a aplicar, principalmente porque la niña mejoró en pocos meses y porque se vio innecesario, en el momento en que se encontraba la familia, movilizar una temática que requería la rememoración de aquellas situaciones que ocasionaban el estrés postraumático.

Fueron fundamentales para su mejoría sus figuras de apego, atentas a sus cuidados básicos y afectivos. Cabe destacar que paralelo a Arteterapia, la psicóloga de Cruz Roja Málaga, junto con los padres, estaban aplicando diariamente distintas estrategias de modificación de conductas. Es algo que es importante de mencionar, primero, porque el Arteterapia debe ser contextualizada y, segundo, porque es fundamental el trabajo en equipo. Pudimos observar que la mirada de los padres cambió cuando pudieron entender, a través de la psicoeducación, que lo que la niña mostraba eran indicadores de estrés postraumático. Fue fundamental que los padres se sintieran apoyados ante tanto desborde conductual.

Se trabajó con Arteterapia psicodinámica, principalmente no directiva. Las sesiones tuvieron una duración 45 minutos, una vez por semana, durante nueve meses. Se realizaban en una ludoteca pequeña, por tanto, en casi todas las sesiones los juguetes formaban parte de la terapia. Al principio se insistía más en acercarla al material plástico, pero con el paso de las sesiones, se permitía cierta flexibilidad, debido al aspecto práctico del espacio, rodeado de juguetes y también porque una parte importante del trabajo era fomentar una conducta lúdica.

Los juguetes que formaron parte de las sesiones fueron; una casita donde ella se metía con los juguetes o con los materiales (y que pretendía que permaneciese fuera, sobre todo en las primeras sesiones, aunque se repitió a lo largo de los 
meses); la cocina de juguete y sus utensilios, y muñecas/muñecos. Al principio, o jugaba con los materiales plásticos o con los juguetes pero tardó alrededor de un mes o dos meses en realmente implicarse con los plásticos. Fue interesante ver la evolución del proceso terapéutico donde, tanto los juguetes como los materiales plásticos, se fueron integrando en un mismo juego.

Destacar que trabajamos con los materiales y el soporte sobre el suelo sin mesa, con lo cual esto también pudo haber influido en la forma de interacción, aunque, por otro lado, trabajando con otros niños en el mismo espacio, su forma de interaccionar con el material era bastante peculiar y reiterada.

La experiencia que tiene cada persona con el material es muy particular y dependerá de su experiencia personal. Para esta niña, en un principio por la hiperactividad, se pensaba que le iba a ir muy bien la arcilla, y de hecho se le ofreció en las primeras sesiones, pero a pesar de que en ocasiones la utilizó, no le terminó de agradar su textura. Más bien hacia el amago de moldear pero luego desistía. Lo que más le atrajo fue el tacto de las témperas en las manos.

\section{Lenguaje no-verbal}

Como muestra las definiciones de las principales asociaciones profesionales de Arteterapia, a nivel nacional e internacional, tradicionalmente el Arteterapia se ha recomendado a personas que por diversos motivos no pueden realizar una terapia convencional, es decir una terapia verbal. Es el caso de los niños, dónde el arte es un lenguaje cercano y, por otro lado, con algunas personas con diversidad funcional por las dificultades de vinculación verbal. También es recomendado para personas que están pasando por situaciones difíciles donde no hay palabras para describir lo que sucede como pueden ser trauma, duelos, enfermedades físicas, cuidados paliativos, etc.

El caso práctico que presentamos cumple con este criterio, dado que se trata de una niña pequeña y cuya lengua principal no era español, se encontraba aprendiendo el idioma y llevaba poco tiempo en España. De hecho las primeras sesiones me hablaba en su idioma incluso sabiendo que no le podía entender.

Un breve trasfondo a la psicología del desarrollo nos ayuda a contextualizar la importancia del lenguaje no-verbal en todas las personas y su posibilidad de cambio. En los primeros años de vida, antes del desarrollo del lenguaje, el aprendizaje es en base a sensaciones y experiencias corporales. Por ejemplo, los afectos vitales ${ }^{2}$ en infantes descritos por Stern (2000) donde a través de la relación implícita con el cuidador (cualidad de los movimientos del cuerpo del cuidador, expresiones faciales) se aprende a regular y otorgar sentido a la intensidad de las sensaciones corporales, paso previo para desarrollo psíquico del bebé.

Cuando el bebé descubre el maravilloso mundo del lenguaje se encuentra con ventajas y desventajas. La principal ventaja de adquirir el lenguaje es la independencia, la libertad y la posibilidad de interacción social y cultural. El

2 Los afectos vitales son variaciones de diversas experiencias kinestéticas y se derivan de la experiencia somática del bebe de placer/ displacer y de los procesos corporales como respirar, latidos del corazón, pulso, dormir, "rising \& declining of the body". Algunos ejemplos de afectos vitales son; explosión, debilitamiento, fugocidad, distanciamiento, crescendo, decrescendo etc... (Chui Yee Joy Chong, 2015). 
lenguaje es categórico, separa la realidad de uno mismo y la ubica en un tiempo. Permite separar el pensamiento de la emoción. Puede explicar experiencias no verbales pero no es capaz de representarlas en su totalidad, como por ejemplo las contradicciones o experiencias que son ricas y llenas de matices. La experiencia verbal frente a la no-verbal son como "dos versiones diferentes del mismo acontecimiento" (Stern, 1999, p. 112).

\section{Neurociencia y trauma}

Las investigaciones sobre el funcionamiento del cerebro y el procesamiento de memorias traumáticas nos abren una ventana más para comprender y sustentar nuestro trabajo. A través de la experiencia con personas que han sufrido situaciones traumáticas se ha podido observar cómo las situaciones quedan guardadas en nuestra memoria de forma segmentada y sin conexión entre sí, debido a la segregación de hormonas de estrés.

Esto hace que se desarrolle un trauma psicológico dado que de forma natural la persona no ha podido consolidar un recuerdo o narrativa del suceso, ubicado en un espacio-temporal. Las memorias de carácter kinestéticos, asociados a los sentidos, no quedan integrados al suceso. La persona vive en un estado de alerta estimulado por recuerdos que ni siquiera tiene conciencia de su relación con experiencias pasadas.

En Estados Unidos se han desarrollado diversos protocolos de Arteterapia, "Trauma Informed Art Therapy", para el trabajo con personas con trauma bajo esta perspectiva de interacción cuerpo-mente. Con las artes plásticas se pretende facilitar conectar estas memorias que han quedado segmentadas a consecuencia del estrés sufrido (Malchiodi, 2011).

La Sociedad Internacional para los Estudios de Estrés Traumático (ISTSS), en sus guías de tratamiento, hablan de como el Arteterapia permite una externalización de imágenes internas, pensamientos, y emociones de carácter no- verbal, siempre y cuando la persona se sienta en un espacio seguro y no se encuentra en estado de alerta.

Caroline Case (2015) explica cómo se da esta interrelación en Arteterapia con personas que han sufrido un trauma; puede suceder que una palabra, un gesto, un color, una narración puede despertar una memoria difícil. La misma se podrá trabajar si existe algún grado de similitud entre una vivencia presente, estimulada con los materiales o el espacio, y la situación traumática del pasado. De forma que la experiencia es recordada, y a la vez modificada por la situación actual. Por ejemplo, a través del dibujo se le da forma y contorno a un recuerdo o sensación permitiendo que se exteriorice. La exteriorización permite organizar, pensar, dar sentido, de forma que se vaya facilitando la creación de una narrativa en torno al trauma.

Desde el enfoque de procesamiento de información de la Técnica EMDR "Desensibilización y Reprocesamiento por los Movimientos Oculares", podemos extender estos conocimientos a personas que no han sufrido un trauma pero que han desarrollado un malestar o síntoma; "...la distinción importante que existe entre un suceso procesado adaptativamente o uno almacenado disfuncionalmente es que, en el primer caso, se ha llevado a cabo un aprendizaje adecuado y ha sido 
almacenado con emociones apropiadas, que son capaces de guiar a la persona hacia el futuro. El recuerdo almacenado disfuncionalmente aún guarda dentro de sí algunas de las percepciones sensoriales y pensamientos que prevalecieron durante el suceso mismo" (Shapiro, 2004, p.4).

\section{Experiencias Sensoriales: el uso del material plástico en Arteterapia}

En Arteterapia prestamos atención al uso que se da del material a lo largo de una sesión y de un proceso terapéutico, en adición al proceso creativo y de interacción con el terapeuta.

Los materiales plásticos poseen una gran cualidad sensorial que pone en funcionamiento los sistemas visuales, táctiles, kinestéticos, olfativos y auditivos. Los mismos pueden estimular memorias implícitas, y esto según las personas con quien trabajemos puede ser beneficioso o perjudicial. Como destaca la Arteterapeuta Naff (2014) debemos ofrecer aquellos materiales que se asemejen al tono emocional de la persona con quien trabajemos, y cuando se trabaja con trauma esto es un aspecto esencial de la práctica, dado que algunos materiales pueden despertar memorias asociadas a situaciones altamente estresantes.

En los primeros acercamientos que hacia MA al material impresionaba el uso que hacía, incluso se cuestionó si debía intervenir, de forma que modificara su interacción, dado que en la mayoría de las ocasiones la sala quedaba muy sucia y desordenada y no me quedaba claro del todo si esto era algo beneficioso para ella.

Pintaba sus manos con témperas (siendo sus manos el soporte) y, si se le dejaba, se pintaba todo el brazo. De hecho, en las últimas sesiones llego a pintarse los pies.

En otros niños con experiencias graves, donde su dignidad ha sido violada, no se les permite que se pinten sobre las manos y brazos, sobretodo en un primer momento, dado que son niños con mucha confusión y el hecho de poner límites claros los hace sentir seguros.

En el caso de MA se le permitió pintarse las manos, siempre y cuando no se pintase los brazos, aunque esto podía variar de sesión en sesión, dado que en pocas ocasiones, de manera repentina, ya se había pintado todo el brazo. Igualmente se percibía que lo hacía como una forma de experimentación del material que generalmente es propia de niños más pequeños.

Otro aspecto interesante era el juego que hacía con el agua de limpiar los pinceles. Pasaba agua de un recipiente a otro, probando con diferentes modalidades de recipientes o juguetes. También se pintaba las manos y las limpiaba en el cubo de los pinceles. Con el paso de las sesiones no sólo se pintaba con pincel la mano, sino que echaba los colores a la paleta y de ahí introducía los dedos para pintarse las manos, muchas veces jugaba a que se estaba "enjabonando" las manos para luego meterlas en el cubo del agua. Con el paso de las sesiones se llegó a echar del bote de pinturas directamente a las manos simulando que era jabón, con un color, y luego con otro; siempre observando el resultado de la mezcla de colores y oliendo las manos.

Cada vez que tenía este tipo de interacción con el material se le ofrecía algún soporte (cartón o folio) para pintar, ya fuese con el pincel o con las manos, dependiendo de dónde tuviese las pinturas. En ocasiones se le proponía y lo utilizaba, o no, y en otras era ella quien lo pedía. 


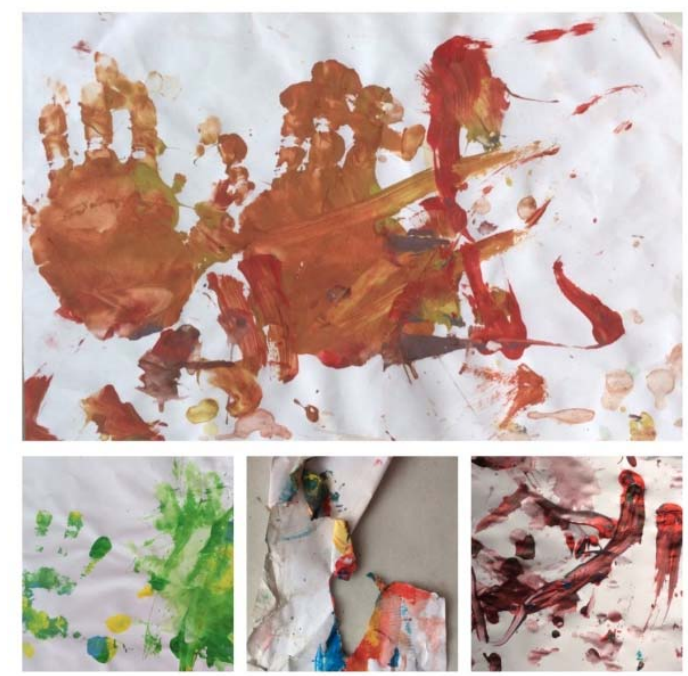

Figura 1. Primeros trabajos con témperas producto de las acciones de pintarse las manos.

En términos de desarrollo evolutivo del dibujo y/o modelado hasta los dos años de edad aproximadamente un niño no tiene la intención de hacer algo, interactúa con el material a modo de experimentación atraído por la experiencia motora kinestésica y sensorial en sí misma, como por ejemplo el movimiento locomotor de los brazos, manos y cuerpo; a esta etapa se le conoce como la manipulativa. Con el tiempo, cuando se va dando cuenta que es quien realiza las marcas, le va atrayendo los aspectos visuales, es decir las marcas y señales que deja (Aron Rubin, 2005). De ahí va repitiendo marcas o signos hasta que va desarrollando variaciones y eligiendo las que más le atrae.

Aunque el proceso evolutivo del desarrollo del arte no es algo lineal, este aspecto de experimentación propia de niños, incluso más pequeños que MA, caracterizó las sesiones donde utilizaba los materiales plásticos. Duboswki (1987) afirma que cuando se sufre una situación difícil es posible que se vuelva a etapas pre-representativas del dibujo infantil. Con MA se observaba como sentía la pintura en sus manos, observaba, y la olía; la impresión que daba era que, de repente, se paraba el tiempo, venía la calma y todo lo demás perdía importancia.

Como explica Noemí Martínez Díez (2012) la pintura tiene una cualidad atemporal y efímera; es recomendable que niños hiperactivos pinten con la manos porque les hace "...tomar una nueva conciencia sobre su propio cuerpo y sobre el yo" (p. 131). Creemos que, en un primer momento, la pintura "en las manos" y "con las manos" permitía a MA detenerse y experimentar aspectos esenciales de su desarrollo evolutivo.

\section{Sobre ensuciar y desordenar en Arteterapia}

Leyendo a la arteterapeuta Obrien (2004), según su experiencia en el trabajo con niños, las acciones de ensuciar y desordenar permiten acceder a memorias preverbales de experiencias caóticas asociadas al abandono y negligencia en la 
primera infancia. Destaca como algunos niños necesitan compartir esta experiencia sensorial con el terapeuta como una forma de relacionarse.

En el caso de MA no hay un trasfondo de abandono ni de negligencia pero sí de privación de un infancia libre de estrés; si vives en un sitio donde están bombardeando, el sentido de supervivencia es el que prima, por tanto los niveles de estrés son muy altos para permitir que un niño pueda desarrollarse de la forma más óptima posible.

En MA había una necesidad imperiosa de compartir su experiencia, dado que siempre invitaba a pintar la mano de la terapeuta y a introducirla en el agua. En un primer periodo se participaba de esta invitación, aunque paulatinamente se dejó de hacerlo, y solo se le acompañaba, velando que no mojara demasiado ni pintara el mobiliario.

En el artículo "Chocolate or Shit" de Aldridge (1998) habla del caos y el ensuciar como una forma de exteriorizar el desorden que se siente por dentro, o como una forma de probar límites y distinguir entre sensaciones internas y corporales. Creemos que el tema de probar límites y comprobar si tienes al lado un adulto, que te contenga lo suficiente, forma parte de este juego lúdico. Hace falta una figura externa que haga de filtro de contención ante el desborde emocional que se pueda estar sintiendo, para que de alguna forma ese otro sirva de espejo y de sostén.

En este caso, lo interesante fue ver como los límites que se ponía los fue incorporando de forma que ella comenzó a ponérselos a sí misma. Por ejemplo, llevaba mucho papel de periódico por el agua que caía al suelo, ella con el tiempo era quién buscaba dicho papel y lo colocaba en el suelo. Si fuese por ella, llenaba los cubos de agua hasta arriba y la terapeuta era quién constantemente tenía que estar recordando que echara menos agua porque iba a caer demasiado sobre el suelo. Aunque era un proceso que iba y venía, ella misma era capaz, en ocasiones, de controlar cuánta agua traía a la sala.

Con niños con experiencias muy difíciles en la primera infancia (Machioldi), en ocasiones no tienen asociados experiencias positivas a las sensación corporales, por tanto se recomienda que, en una primera fase de trabajo, facilitar el disfrute y dominio del material. Permitir la repetición dado que hace sentir al niño como un agente de cambio y de control, fomentando así el empoderamiento de forma que se pueda contrarrestar sensaciones de vulnerabilidad e impotencia.

En ocasiones, el material funciona como un autoregulador de emociones, reduciendo el estrés y la sensación de estar en alerta. Poder ofrecer actividades que disminuyan el estado de hiperactivación es un aspecto fundamental al trabajar en un primer momento de la terapia con niños que han sufrido experiencias difíciles.

Esto claramente lo pude observar con MA y luego de esta lectura la mirada de la sesión cambio drásticamente. Se pudo observar que a quien más ansiedad le causaba el desorden y el sucio era a la terapeuta y no a la niña.

Otra característica del trabajo con niños y con pinturas es la asociación que hacen a la comida y al excremento, aunque el significado puede variar mucho. Hay situaciones en el que el hecho de mezclar todos los colores lleva a jugar con asociaciones como si fuera caca. En algunos es un tema de exploración del material y de sus cambios, y en otros para ver qué sucede y cómo responde el terapeuta ante dos elementos que no son socialmente aceptados: sucio y caca (Aldridge, 1998). 
El juego con MA comenzó a evolucionar de forma que estaba interrelacionado el uso del material con el de los juguetes. El cubo de enjuagar los pinceles se convertía en la olla donde cocinar, donde metía objetos que traíamos para hacer collage como tapitas, y que hacían la función de comida. El agua de los pinceles en ocasiones era cola cao, gazpacho o café... Y de ahí el juego era que ella cocinaba y me daba de comer o comíamos juntas. Esto casi que se convirtió en un ritual, usaba las pinturas en la mano, pintaba algo, hacía que se enjabonaba las manos con pinturas, se la lavaba en el cubo de los pinceles y luego preparaba comida.

Pensamos que era claro que el Arteterapia jugaba un papel especial para ella y que de alguna forma quería también nutrir el espacio con su comida. A la vez que puede representar un ensayo de roles, dado que jugaba mucho a que cocinaba y limpiaba, o intercambiaba los roles donde ella era la bebé y yo el adulto.

En las últimas sesiones comenzó a utilizar mucho más la arcilla, bien porque la pintura ya se estaba terminando o porque el tiempo de experimentación con las pinturas le facilitó retomar la arcilla incluso cuando en un comienzo le desagradaba su textura, decía que estaba muy dura.

Cuando se acercaba el final de la terapia comenzó a utilizar la arcilla y el rodillo, jugaba a que era caca y que lo pegaba por los brazos de la terapeuta. También introducía un trozo sobre el cubo de los pinceles y veía el efecto en el agua, agua que se convirtió una vez más en comida.

\section{Pasar de la experimentación a la obra plástica}

En Arteterapia una de las tareas con este colectivo es llevar la acción o actuación a la obra plástica (o al material). Sobre este aspecto ha aportado mucho el modelo Nordoff-Robbins de Musicoterapia, dado que parte de la premisa que no hay resistencias en la persona en terapia, y que casi toda acción se puede transformar en algo creativo.

Con MA el primer reto era pasar de la acción inquieta al juego y el segundo pasar de la experimentación con la pinturas en la mano al soporte, y el tercero era mantener los límites de forma creativa. Por ejemplo, que pudiera experimentar con las pinturas y el agua sin dañar mobiliario o cuando intentaba pintar un juguete ofrecerle algo tridimensional para pintar.

En el caso de MA, cuando se encontraba en el momento de exploración con las pinturas y el agua, pensábamos que lo más adecuado era ofrecer un folio e invitarla a pintar algo, aunque claramente percibía que no era algo que le llamase la atención. Pero se entendía que era importante siempre ofrecer la posibilidad de crear algo dado que de ello se fundamenta nuestra metodología.

Vemos oportuno apoyar la experimentación pero también facilitar la creación de una obra tangible; dado que a través de la obra puede separarse de sí, y devolverle un contenido o un significado. La separación en términos evolutivos es lo que permite desarrollar un sentimiento de identidad individual (Case, 2003). Me parecía importante que a través del acompañamiento a la experimentación, sin forzar el proceso, pudiese pasar de la experiencia corporal a la representación. De alguna forma es darle la posibilidad de desarrollar un recurso creativo que le pueda servir fuera de Arteterapia.

Por otro lado cabe destacar que, paralelo al proceso de pintar en un soporte, el 
hecho de realizar un juego a partir del material es también una forma de representación, y forma parte de la función de fomentar un espacio lúdico y creativo donde ella pudiera colocar sus ansiedades o preocupaciones.

En mi opinión la obra de arte ocupa un segundo plano en relación con el acto de producirla. La primera preocupación del terapeuta debe ser el proceso creativo. En el caso de niños pequeños, quizás el problema inicial consista en ayudar al sujeto a adquirir las actitudes necesarias para efectuar signos dotados de significado, significativos antes que nada para el niño y sólo después para el terapeuta (Dubowski, p.100).

Según O'Brien (2004) el ser acompañantes y testigos de las producciones plásticas hace que sensaciones físicas envueltas en el proceso de la terapia se conviertan en palabras y pensamientos que organicen la vivencia de una persona.

Una vez MA puede bajar su estado de alerta, disfruta de la experiencia sensorial del tacto con la pintura y el agua, y también va poco a poco a pedir un soporte para pintar ya sea con manos o con pincel. De lo sensorial pasa a la experiencia compartida, de la experiencia compartida pasa al juego y del juego a la representación. No es un proceso lineal, sino un proceso que va y viene, incluso en una misma sesión. De alguna forma es restaurar ese desarrollo evolutivo que se da de forma natural en los niños y que pudo haber quedado interrumpido por situaciones de estrés. Es otorgar "...la oportunidad de experimentar y de jugar mediante la conducta de realización de signos" (Dubowski, p.106).

El papel se convierte a su vez en un espacio que posibilita el desarrollo simbólico del niño mediante la metáfora y la metonimia, mecanismos ambos del proceso de significación. El papel se convierte en un espacio donde el niño puede inscribirse, decirse y significarse. Del mismo modo, el trazo se convierte en objeto que nos liga-desliga de nosotros mismos, que nos une al otro en una interrelación de significados. Se convierte en objeto simbólico al cual investimos de contenido personal e inaugura el juego, inicio de la cultura. (López Fernández Cao, 2012, p. 111)

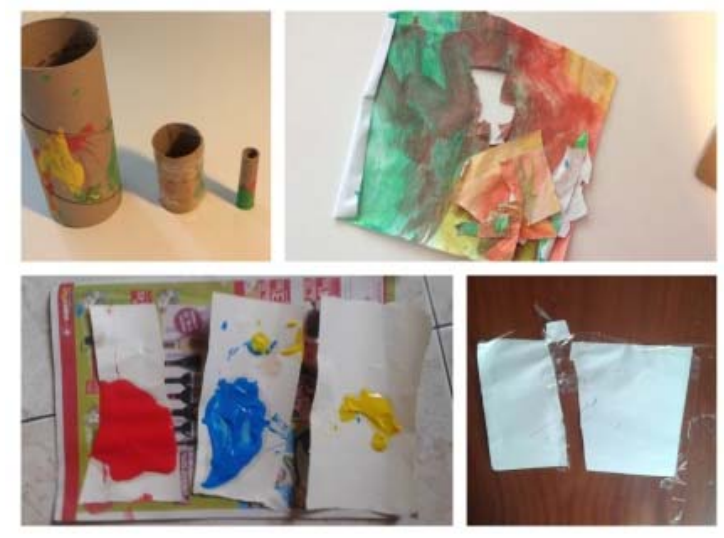

Figura 2. Trabajos con témpera que reflejan intencionalidad. 
Cuando podemos salir de nosotros mismos, canalizar lo que quedó impreso en el cuerpo, podemos compartir y estar en el afuera. Estar en el afuera significa detenerse, interactuar, poder vincularse y socializar.

El convivir transforma nuestro lenguaje, nuestras creencias y, también nuestro mundo sensible. Esta participación es inconsciente y extremadamente variable. Hacer arte exige volver consciente, visible, esa sensibilidad, ponerla en imágenes, tomar posición, elegir sus posibilidades y variaciones y, finalmente, corporizarla en el trabajo con la materia. Estas etapas, lejos de formar una secuencia, se alimentan mutuamente para darle vida a la obra. Gracias al artificio de la arteterapia, el artistant se ubica en el momento del despertar a lo sensible para poder superar sus obstáculos personales, tanto en la recepción del mundo sensorial como en su materialización (Pain, p.39).

\section{Registro del trabajo plástico}

El arte se convierte en algo concreto que permanece y puede ser visto en otro momento. En usuarios que tienden a la negación de lo que están sintiendo, luego de pasar un tiempo y volver a observar la obra, pueden reconocer y ver aquello que en su momento no estaban preparados para enfrentar, como puede ser una emoción profunda de abandono o vulnerabilidad (Chui YeeJoy Chong). Se acompaña el proceso de creación sin forzar y solo se promueve la reflexión cuando observemos que la persona está preparada; dado que en caso contrario pueden resultar que la persona se sienta incomprendida, rechazada o simplemente generar una reflexión superficial.

A pesar de que en ocasiones en una sesión de Arteterapia no se crea ningún objeto tangible, ya sea porque la persona no lo ha hecho, o porque lo ha tirado a la basura, o porque algunos terapeutas utilicen técnicas más contemporáneas como la "perfomance", me pregunto si siempre se debe registrar dicha experiencia, dado que no todo se puede registrar. Diferentes arteterapeutas utilizan diferentes aproximaciones, por ejemplo a quienes toman foto de la obra en la sesión para que quede registrado "la improvisación", y otros la toman luego de que termine la sesión.

En este caso tomamos la fotografía del trabajo de MA una vez que terminaba la sesión. Este registro visual permitió ver la evolución de sus pinturas y sus trazos en la terapia que en ocasiones se perdía de perspectiva dentro del caos y sucio de la sesión.

Se pudo corroborar como comenzó a haber un proceso intencional de combinar colores, pintar sobre el soporte, probar diferentes pinceles y trazos, y observar sus efectos. También como comenzó a incorporar acciones como cortar la obra pictórica en trozos, y también pegar algunas partes con papel celo; se vio el paso de lo vivencial y experiencial a lo tangible e intencionado. 


\section{Conclusiones}

Con esta niña fue fundamental ofrecerle un espacio de juego y experimentación libre sin sentirme amenazada por tanta energía y desorden. El trabajo fue de ofrecerle un espacio potencial para experimentar en términos evolutivos lo que situaciones de estrés no le permitió experimentar en su totalidad. Esto es una tarea muy simple pero fundamental. Para ello fue necesario promover aquellas actividades que la traían al aquí y al ahora, que le permitieran bajar su activación corporal, y por tanto pudiese simplemente jugar. A través del juego, primero pudo experimentar sin temor a ser castigada por el desorden, para poco a poco poder recrear y representar situaciones en las que se sentía nutrida, podía ser débil, se podía cobijar, o también podía ser mala y cruel.

La hiperactividad hace que no podamos ver a un niño como es, por lo molesto que resulta, en este caso escondía del resto de personas una niña con una gran sensibilidad y una capacidad de actuar y empatizar por el otro. Recuerdo un día que fui con un el brazo lastimado y ella tuvo mucho cuidado del juego que realizaba para no lastimarme, también dibujó por primera vez una representación de un muñeco con sus amigos cortando sus brazos y volviéndolos a pegar. Podríamos añadir una lectura adicional a su forma de experimentar, y es que aún mantiene la gran capacidad de "comprender las cosas por medio de los sentidos" (López Fernández Cao, p. 189), cosa que el resto de personas vamos perdiendo.

Arteterapia es una poderosa disciplina pero como toda terapia tiene también sus limitaciones, no todo lo puede abarcar, como por ejemplo, quien se encarga del comportamiento de la niña fuera de la sesión con padres que se sienten desbordados. Cuando el trabajo se extiende fuera de la sesión, con los padres y el entorno, una simple tarea como por ejemplo, lograr cambiar la mirada que tienen del niño o simplemente que puedan pensarlo de otra forma es ya un gran logro alcanzado. Esto fue un aspecto fundamental y parte de ello lo conformo la psicoeducación.

La intención de este artículo es comenzar a plantear los procesos que se dan en Arteterapia propios de la disciplina, para ello han sido necesario incluir el proceso creativo de interacción con el material, el proceso de la relación con el terapeuta y con el espacio.

En concreto se ha querido discutir los aspectos no verbales y prerepresentacionales de Arteterapia, que permitieron un cambio significativo en la persona. Cada caso y manera de interactuar con un material dependerá de la historia particular de la persona. Lo que para esta niña era algo agradable que le ayudaba a canalizar su energía y a tranquilizarse, para otro niño puede ser una fuente de angustia.

Hemos hecho un breve recorrido sobre las aportaciones del trauma y de la neurociencia, pero sería interesante ampliar este recorrido a personas que no han sufrido trauma. De otra forma, más superficial, nos preguntamos si con estas personas se produce un cambio con una intervención no-verbal, en ocasiones se pasa a la palabra y en otras no, porque no podría funcionar con otros colectivos.

Uno de los aspectos que llaman la atención de esta disciplina es el respeto a la persona y su historia. Es decir, no somos quienes le decimos qué ocurre y qué tiene que cambiar; acompañamos a la persona a construir su propio camino. Facilitamos 
y promovemos un proceso creativo, que pertenece a toda persona, que ayude a externalizar y materializar aquello confuso que no le deja funcionar de la forma más óptima posible.

\section{Referencias bibliográficas}

Aron Rubin, Judith (2005). "Child Art Therapy". New Jersey: John Wiley \& Sons, Inc.

Aldridge, Felicity (1998). Chocolate or Shit: Aesthetics and cultural poverty in art therapy with children. International Journal of Art Therapy, Inscape, 3 (1), 2-9.

Case, Caroline (2005). The mermaid: moving toward reality after trauma. Journal of Child Psychotherapy, 31 (3), 335-351.

Case, Caroline (2003). Authenticity and suvival working with children in chaos. International Journal of Art Therapy, Inscape, 8 (1), 17-28.

Chui Yee Joy Chong (2015). Why art psychotherapy? Through the lens of interpersonal neurobiology: The distinctive role of art psychotherapy intervention for clients with early relational trauma. International Journal of Art Therapy, Inscape, 20 (3), 118-126.

Dubowski, J.K. (1987). Modelos alternativos para la descripción del desarrollo de la representación gráfica en los niños: Algunas implicaciones para la terapia artística. En T. Dalley (Ed.). El arte como terapia (p. 95-113). Barcelona: Herder.

ISTSS International Society for Traumatic Stress Studies. Guideline 17: Creative Arts Therapies for Children; Recuperado de https://www.istss.org/ISTSS_Main/media/Documents/ISTSS_g17.pdf

López Fernández Cao, M., y Martínez Díez, N. (2012). Arteterapia Conocimiento interior a través de la expresión artística. Madrid: Ediciones Tutor.

Malchiodi, Cathy (2011). Trauma Informed Art Therapy and Sexual Abuse in Children. En Paris Goodyear-Brown (Ed.), Handbook of Child Sexual Abuse: Prevention, Assessment, and Treatment (p. 341-354). New York: Wiley.

Naff, Kristina. A (2014). Framework for Treating Cumulative Trauma with Art Therapy. Art Therapy. Journal of the American Art Therapy Association, 31 (2), 79-86.

O'Brien, Frances (2004). The making of mess in arte therapy: Attachment, trauma and the brain. International Journal of Art Therapy, Inscape, 9 (1), 2-13.

Pain, Sara (2008). En el Sentido Figurado; Fundamentos Teóricos de la Arteterapia. Buenos Aires: Paidós.

Raby, C., y Edwards, D. (2011). Unrecognized hospital trauma as a source of complex psychiatric symptoms: A systematic case with implications for children's right and evidence-base practise. Psychotherapy Research, 21 (5), 541-553.

Shapiro, Francine. (2004). EMDR Desensibilización y reprocesamiento por medio del movimiento ocular. México: Editorial Pax.

Stern, Daniel N. (2000). The interpersonal word of the infant. New York: Basic Books.

Stern, Daniel N. (1999). Diario de un bebé: Qué ve, siente y experimenta el niño en sus primeros cuatro años. Barcelona: Paidós. 